\section{Patterns of responding in conditioned reinforcement schedules superimposed} on primary reinforcement schedules*

\author{
DONALD W. ZIMMERMAN \\ Carleton University, Ottawa 1, Canada
}

Rats responded on a 2 -min fixed-interval schedule in which lights were associated with water reinforcement at the end of each interval. Rate changes resulting from superimposed conditioned reinforcement schedules were examined under conditions in which momentary stimulus effects were minimized. When a variable-interval schedule of presentation of lights, without water, was superimposed on the fixed-interval schedule only during alternate intervals between water reinforcements, overall rate of responding increased in all intervals, including those in which stimuli were not added. When lights, without water, were presented on a similar variable-interval schedule during alternate intervals, only after at least 6 sec had elapsed since a response (DRO schedule), overall rate decreased in all intervals. When a single response-dependent stimulus presentation was added in the middle of each interval between water reinforcements, rate decreased in periods just after the added stimulus and increased in periods just before the next scheduled presentation of the stimulus.

When rate of responding increases after response-dependent presentations of a stimulus which has been associated with primary reinforcement, it is sometimes not possible to conclude that conditioned reinforcement has occurred Effects of a stimulus other than reinforcement, including frustration and facilitation, can be invoked to account for increases in rate (e.g., Bugelski, 1956; Schuster, 1969). According to these interpretations of conditioned reinforcement, the rate increase can be a momentary change, occurring in a brief period just after the stimulus presentation, unlike the schedule effects of primary reinforcement.

The present experiment examined rate changes in conditioned reinforcement schedules under conditions in which momentary effects of a stimulus were minimized. First, a two-lever situation was employed in which onset of a stimulus after responses on one lever controlled changeover to another lever, so that for a period just after the onset of the stimulus, the rat was not near the first lever. Second, the schedules were arranged so that increases in rate were obseved in periods remote from the time of onset of the stimulus. Third, schedules which engendered both increases and decreases in rate were studied. Finally, a schedule which resulted in a decrease in rate just after the stimulus presentation, but an increase in rate during a period just before the next scheduled stimulus presentation, was examined.

*Supported by the President's Research Grant from the National Research Council of Canada (2055-55).

\section{METHOD AND RESULTS}

The Ss were four Sprague-Dawley male albino rats, about 90 days old at the beginning of the experiment. They were given daily 1-h sessions, 7 days a week, under 22-h water deprivation. Dry food was continuously available in the home cages.

The apparatus, described previously (Zimmerman, 1969a, b), was a modified Gerbrands Model C- 3 chamber with two levers on opposite panels, $89 \mathrm{~mm}$ above the floor. Reinforcement was provided by a liquid feeder that operated for $5 \mathrm{sec}$ and gave access to $.1 \mathrm{cc}$ of water. Stimuli consisted of two $7.5-\mathrm{V}$ pilot lamps with white crystals located on opposite panels above the levers. The chamber was enclosed in a ventilated ice chest. Responses were recorded on a Gerbrands cumulative recorder and on digital counters.

During the first 11 sessions, a heterogeneous chained schedule was established. At the end of this period, the sequence of events was as follows: Each response on Lever 1 produced a stimulus consisting of onset of two pilot lights. The first response on Lever 2 terminated the lights and produced water. Next, a 2-min fixed-interval schedule (FI 2-min) was established on Lever 1 . The first response on Lever 1 after a 2-min interval since the last reinforcement produced the lights, and the first response on Lever 2 terminated the lights and produced water. On each occasion, the lights remained on until a response on Lever 2 occurred, and during this period, responses on Lever 1 had no scheduled consequences. After the initial training period, a response on Lever 2 occurred, almost invariably, a few seconds after presentation of the lights.

The experimental procedures are summarized in Table 1 . Under the FI 2-min schedule of presentation of lights and water, there was a typical pattern of positively accelerated responding. Beginning in the 20 th session, responding in successive 15 -sec intervals during alternate intervals of the FI 2-min schedule was recorded. That is, rate was recorded in each one-eighth of the 2-min interval between water reinforcements in every second interval.

Beginning in the 34 th session, a variable-interval schedule of lights, without water, was superimposed on the FI 2-min schedule in alternate intervals, and responding was recorded in those intervals when the variable-interval schedule was not added. The schedule was an arithmetic series, with a mean interval of $30 \mathrm{sec}$ (VI 30-sec). Responses on Lever 1 produced the lights on this schedule; on each occasion, the first response on Lever 2 terminated the lights but did not produce water. The original FI 2-min schedule also continued; the first response on Lever 1 after 2 -min intervals produced the lights, and the first response on Lever 2 on these occasions terminated the lights and produced water. When the VI 30 -sec schedule of presentation of lights, without water, was added in alternate intervals, rate increased in all intervals, including those in which stimuli were not added.

In the 48 th session, the superimposed schedule was changed to Tand VT 24-sec DRO 6-sec, where VT denotes variable time periods. That is, the lights were presented after intervals which were similar to those of the VI 30-sec schedule but not immediately after a response on Lever 1 . The lights came on only if a response had not occurred in the preceding 6-sec period at the scheduled time of presentation; otherwise, they were postponed another 6 sec by each response. Again, responding was recorded in the

Table 1 Summary of Procedures

\begin{tabular}{lll}
$\begin{array}{c}\text { Schedule of } \\
\text { Presentation } \\
\text { of Water }\end{array}$ & $\begin{array}{c}\text { Schedule of } \\
\text { Presentation } \\
\text { of Lights }\end{array}$ & \\
\hline FI 2-min & Alternate Intervals) & Sessions \\
FI 2-min & VI 30-sec & $20-33$ \\
FI 2-min & Tand VT 24-sec & $\mathbf{6 2 - 7 5}$ \\
FI 2-min & DRO 6-sec & $48-61$ \\
\hline
\end{tabular}




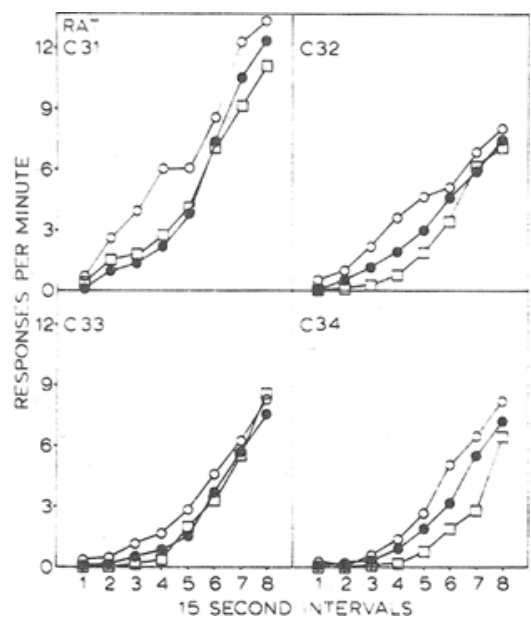

Fig. 1. Mean response rate in each of eight successive 15-sec intervals during alternate $2 \cdot \mathrm{min}$ fixed intervals between water reinforcements under each of three schedules. Solid circles: lights and water presented on FI 2-min. Open circles: lights and water presented on FI 2-min; lights presented on VI $30-\mathrm{sec}$ during alternate 2-min intervals. Squares: lights and water presented on FI 2-min; lights presented on Tand VT 24-sec DRO 6-sec during alternate 2-min intervals.

intervals of the FI 2-min schedule when the DRO schedule was not added. When the Tand VT $24-\mathrm{sec}$ D R O 6-sec schedule was superimposed, rate decreased in all intervals.

Figure 1 shows results of these three schedules (Rats C-31, C-32 C-33, and C-34). The figure plots the mean response rate of each rat, in successive 15 -sec intervals throughout the $2 \cdot \mathrm{min}$ fixed interval between presentations of water, during the alternate intervals in which there were no added stimulus presentations. Averages were taken over intervals in the last eight sessions of each procedure. All four rats responded at a higher rate when the VI 30-sec schedule of presentation of lights was superimposed. After the VI schedule was added, rate usually about doubled in the early intervals and became slightly higher in the later intervals. Under the DRO. schedule of presentation of lights, two rats responded at about the same rate as under the original FI schedule and two rats responded at a lower rate.
Beginning in the 62nd session, the original FI 2-min schedule, without the variable-interval schedule of presentation of lights, was in effect again. Responding was recorded in all intervals between water reinforcements, instead of in alternate intervals. When responding had become stable, without systematic change from one day to another, a FI 1-min schedule of presentation of lights was superimposed. That is, a single response-dependent stimulus presentation was added in the middle of each 2-min interval between water reinforcements. After a 1-min period, the first response on Lever 1 produced the lights and the first response on Lever 2 terminated the lights but did not produce water. After another $1 \cdot \min$ period, the first response on Lever 1 produced the lights and the first response on Lever 2 terminated the lights and produced water.

In this procedure, rate decreased in periods just after the added stimulus and increased in periods just before the next scheduled presentation of the stimulus. The fixed-interval curvature, characteristic of the FI 2-min schedule, was disrupted and curvature appropriate to a FI 1 -min schedule was apparent. Results of this procedure are shown in Fig. 2. Averages were taken over all intervals of the FI 2-min schedule in the last eight sessions of the procedure.

The results of this experiment suggest that the changes were not accounted for by momentary effects of a stimulus. In the first three procedures, the intervals in which responding was recorded always began immediately after water presentation and ended with water presentation; the superimposed schedule in the preceding intervals was manipulated. The added stimuli apparently altered the pattern of responding throughout the overall FI schedule. Rate increased or decreased during the 2-min fixed intervals following those in which stimuli were added. In the last procedure, rate decreased in periods just after a response-dependent stimulus presentation and increased before the next scheduled presentation.

The results of the experiment are consistent with idea that the stimulus was reinforcing and altered the overall pattern of responding, according to the schedule of presentation. They are not consistent with the idea that changes in rate resulted from

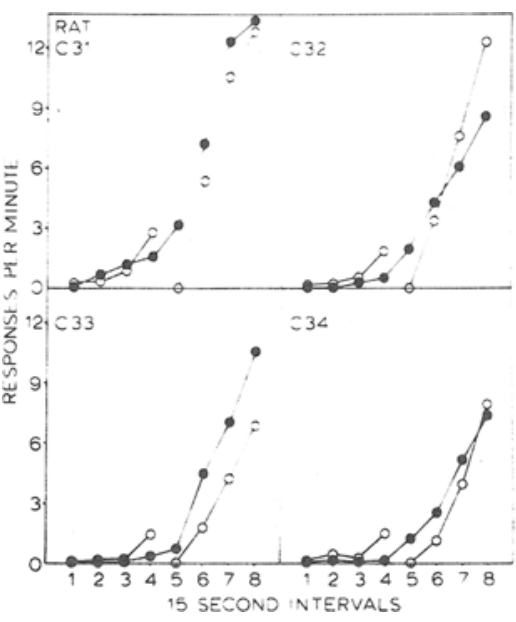

Fig. 2. Mean response rate in each of eight successive 15 -sec intervals of 2-min fixed intervals between water reinforcements under each of two schedules. Solid circles: lights and water presented on FI 2-min. Open circles: lights and water presented on FI 2-min; lights presented on FI 1 -min.

momentary stimulus effects other than reinforcement. Further support for the reinforcement interpretation comes from the fact that after onset of the lights, the rat moved to another lever so that facilitation of responding near the first lever could not occur. Also, the rate on the first lever both increased and decreased, according to the schedule on which the stimulus was presented.

\section{REFER ENCES}

BUGELSKI, R. The psychology of learning New York: Holt, Rinehart \& Winston, 1956.

SCHUSTER, R. H. A functional analysis of conditioned reinforcement. In $D$. $P$. Hendry (Ed.), Conditioned reinforcement. Homewood, Ill: Dorsey, 1969. Pp. $192-234$.

ZIMMERMAN, D. W Pattems of responding in a chained schedule altered by conditioned reinforcement Psychonomic Science, 1969a, 16 , 120-122.

ZIMMERMAN, D. W. Responding in chained schedules maintained by conditioned reinforcement with and without terminal primary reinforcement. Psychonomic Science, 1969b, 17 , 185-187. 